\title{
Research on Control Strategies of PMSM in Electric State for Hybrid Electric Vehicles
}

\author{
Tingting Liu ${ }^{1, *}$, Guojin Chen ${ }^{1}$ and Shigang $\mathrm{Li}^{2}$ \\ ${ }^{1}$ School of Mechanical Engineering, Hangzhou Dianzi University, Jianggan District, Hangzhou, 310018, China \\ ${ }^{2}$ College of Mechanical and Electrical Engineering, Beijing Union University, Haidian District, Beijing, 100083, China
}

\begin{abstract}
This paper mainly focuses on the analysis of permanent magnet synchronous motor (PMSM) and its control system, based on the mathematical model of PMSM, a subsection control strategy is designed for PMSM in electric state, which is a combination of $i_{d}=0$ control and weak magnetic control, in order to get a large speed range and get higher output power in the constant power region. The experiment platform of control system is built, the closed-loop control of the driving system for 2.5kw PMSM is realization, load control experiments that run below the base speed and no-load weak magnetic operation experiments that run above the base speed are carried out, phase current waveforms and weak magnetic control waveforms verify that the control strategy in this paper is correct and could achieve the desired control objectives.
\end{abstract}

Keywords: PMSM; Electric state; Vector control; Weak magnetic control.

\section{INTRODUCTION}

Hybrid electric vehicle (HEV) as a solution to vehicle energy saving have quickly become the new hot spot of automotive development. Motor driving system is the core of HEV power system, in a variety of drive motors, PMSM with its high efficiency, high power density and high reliability becomes more and more popular for motor driving vehicles, thus it is of great significance to study the driving control technology of PMSM for HEV [1].

According to the performance requirements of HEV, in this paper, we take the surface permanent magnet synchronous motor (SPMSM) as the research object, the control strategies of PMSM in electric state are analyzed; based on the features of electric operation state, the subsection control strategy which is suitable for the SPMSM is designed, the experiment platform of control system is built, weak magnetic operation experiments are carried out, so as to improve the output of constant power region and expand the range of adjustable speed.

\section{MATHEMATICAL MODEL ANALYSIS OF PMSM}

The PMSM discussed in this paper is limited in the following cases: ignoring the core saturation and machine winding leakage inductance; supposing the magnetic potential in the air gap is in sine distribution; neglecting the higher harmonic wave in magnetic field. Under these assumptions, using the coordinate transformation principle, we could get PMSM's mathematical model in two-phase synchronous revolution coordinate system, the mathematical model is shown in formula (1), (2), (3) [2].

$$
\begin{aligned}
& U_{d}=L_{d} \frac{d i_{d}}{d t}-\omega_{r} L_{q} i_{q}+r_{s} i_{d} \\
& U_{q}=\omega_{r} \psi_{f}+\omega_{r} L_{d} i_{d}+L_{q} \frac{d i_{q}}{d t}+r_{s} i_{q} \\
& T_{e m}=p\left[\psi_{m} i_{q}+\left(L_{d}-L_{q}\right) i_{d} i_{q}\right]
\end{aligned}
$$

In this formula, $U_{d}, U_{q}, i_{d}, i_{q}$-voltage and current in $d$ axis and $q$-axis(V, A); $r_{s}$ - the resistance of stator windings( $\Omega$ ); $L_{d}, L_{q}$ - the inductance in $d$-axis and $q$-axis $(\mathrm{H}) ; \psi_{f}-$ the main flux linkage of permanent magnet $(\mathrm{Wb}) ; \omega_{r}$-the rotor angular frequency $(\mathrm{rad} / \mathrm{s}) ; p$-number of pole-pairs of electric machine.

The electromagnetic torque is expressed as a current space vector in the complex plane, there is:

$$
T_{e m}=p\left[\psi_{m} i_{s} \cos \beta+\frac{1}{2}\left(L_{q}-L_{d}\right) i_{s}^{2} \sin 2 \beta\right]
$$

$\beta$ is the angle between current space vector and q-axis, when the current space vector in the second quadrant, that is $0 \leq \beta \leq 90^{\circ}$, the motor in the electric state; when the current space vector in the third quadrant, that is $90^{\circ}<\beta \leq 180^{\circ}$, the motor is in generation state. 


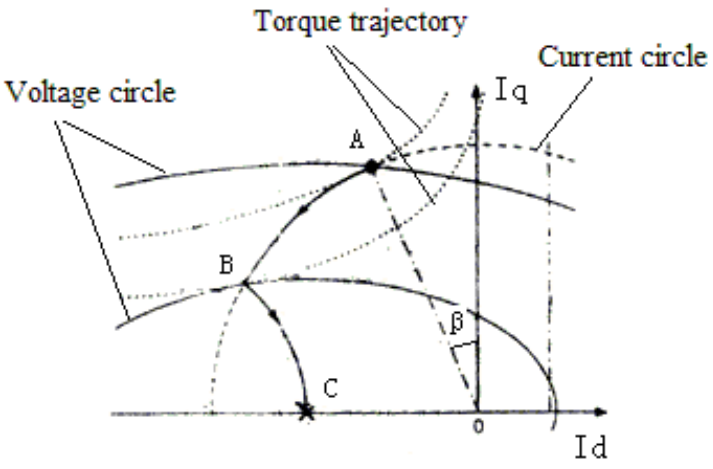

Fig. (1). Circle Diagram of PMSM.

PMSM runs restrained by the voltage and current constraint equations, its operating mode can be divided into three modes.

Voltage constraint equation is:

$\left(L_{q n} i_{q n}\right)^{2}+\left(L_{d n} i_{d n}+\psi_{m n}\right)^{2} \leq\left(1 / \omega_{n}^{2}\right)$

Current constraint equation is:

$i_{d n}^{2}+i_{q n}^{2} \leq 1$

The current and voltage constraint equation are shown in Fig. (1), the current circle trajectory is a circle of radius 1, independent of velocity. Voltage circle path is a group of ellipse tribe, the elliptical area decreases with the increase of rotating speed; the torque trajectory is hyperbola family [3].

Equation 5 and equation 6 require that: Currents on $d$ and $q$ axis must be the intersection of the current circle and the voltage circle; therefore, the current value must be on the current circle or inside. Using the intersection of current circle and voltage circle, the speed of PMSM is determined.

It can be seen from Fig. (1): Mode 1 is the constant torque region. On the circle diagram, point $\mathrm{A}$ is the intersection of the maximum torque circle and current circle, which indicate that, from the 0 to the medium speed area, the PMSM will run in constant torque region, point A within the limit of the current circle; Mode 2 is weak magnetic in region one, the running track of PMSM is in the combined effect of current circle and voltage circle, a series of intersection of ellipse and circle determines the trajectory, that is curve $\mathrm{AB}$ in the circle diagram; Mode 3 is weak magnetic in region two, with the speed continues to increase, the corresponding speed of PMSM over B point, for maximum power, the PMSM will operate along the curve $\mathrm{BC}$, the value of current comes into the current circle, voltage circle plays a role of restriction in this mode.

\section{CONTROL STRATEGIES IN ELECTRIC STATE}

If the parameters of PMSM are identified, the torque is only relevant with currents on $d$-axis and $q$-axis, and for the same torque, there are a variety of combinations, different combinations will affect the output capacity of the inverter and affect the system efficiency, power factor and so on. For the control system of SPMSM in this paper, in order to get a large speed range and greater power output in the constant power region, different control strategies are usually adopted in different working mode. In this paper, a subsection control strategy is designed for PMSM in electric state, which is a combination of $i_{d}=0$ control and weak magnetic control, $i_{d}=$ 0 control is adopted when the PMSM run below the base speed and weak magnetic control is adopted when the PMSM run above the base speed.

\section{1. $i_{d}=0$ Control Strategy}

When $i_{d}=0$, only the $q$-axis component of the stator current exists, the magnetic field space vectors of stator and permanent magnet are orthogonal, only permanent magnet torque component exists. When the PMSM run above the base speed, reduce $q$-axis component of the stator current in order to continue to increase in speed, but the corresponding output torque and output power will decrease rapidly. When $i_{d}=0$, the theoretical maximum speed is shown in formula (7) [4].

$$
\Omega=\frac{u_{\lim }}{\sqrt{\left(p \psi_{m}\right)^{2}+\left(\frac{T_{e m} L_{q}}{\psi_{m}}\right)^{2}}}
$$

\subsection{Subsection Control Strategy}

1 Control strategy in mode $1\left(\omega \leq \omega_{1}\right)$

This mode is constant torque mode. The maximum torque / current control is adopted in this mode, it is also called maximum torque control of unit current, for SPMSM, it is $i_{d}=0$ control.

2 Weak magnetic control in mode $2\left(\omega_{1}<\omega \leq \omega_{2}\right)[5,6]$

The weak magnetic control of PMSM is refers by regulating the stator current to maintain the voltage balance of the higher speed operation, in order to expand the speed 


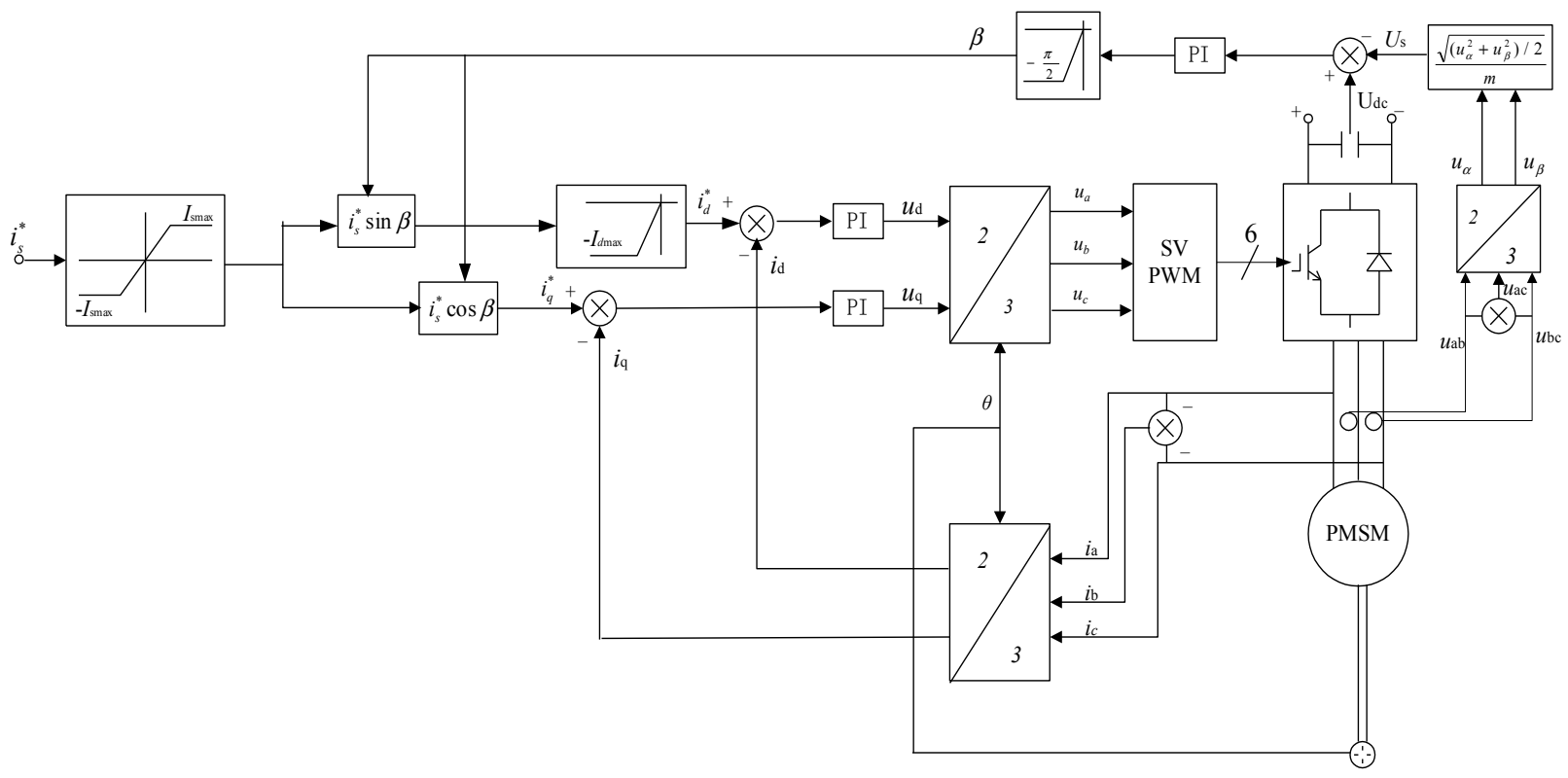

Fig. (2). Diagram of Weak Magnetic Control of SPMSM.

range. When voltage reaches the inverter's capacity limit, regulate $i_{d}$ and $i_{q}$ to improve the speed, this is weak magnetic operation. According the circle diagram of PMSM, the operating mode of SPMSM can be determined, if mode 3 does not exist, as the speed increases, the motor voltage and current circle move counterclockwise along the current circle and ultimately fall on the negative axle shaft, diagram of weak magnetic control is shown in Fig. (2). Compared with $i_{d}=0$ control, there is a voltage PI regulator in this control system, the difference between the stator voltage and DC bus voltage as an input, adjust the difference through the voltage PI regulator to obtain $\beta, \beta$ is the angle between the stator current vector and the $q$-axis. When the terminal voltage of motor is low, voltage PI regulator is saturated, the value of $\beta$ is zero, this is equivalent to $i_{d}=0$ control system, the motor runs in constant torque region. When the terminal voltage of motor increases to a certain value, the input of voltage PI regulator is negative, regulator begins to withdraw from saturation, $\beta$ is negative, which means that the current space vector turn counterclockwise in the $d q$ coordinate plane and forms an angle $\beta$, the $d$-axis component of current is negative, the motor runs in region one of weak magnetic.

3 The maximum output power control in mode 3 [7]

If the SPMSM works at mode 3, in order to enlarge the speed range, the maximum output power control is adopted, stator current in this work region should meet the following formulas (8), (9).

$$
\begin{aligned}
& i_{d}=-\frac{\psi_{m}}{L_{d}}+\Delta i_{d} \\
& i_{q}=\frac{\sqrt{\left(u_{\lim } / \omega\right)^{2}-\left(L_{d} \Delta i_{d}\right)^{2}}}{L_{q}}
\end{aligned}
$$

In these formulas:

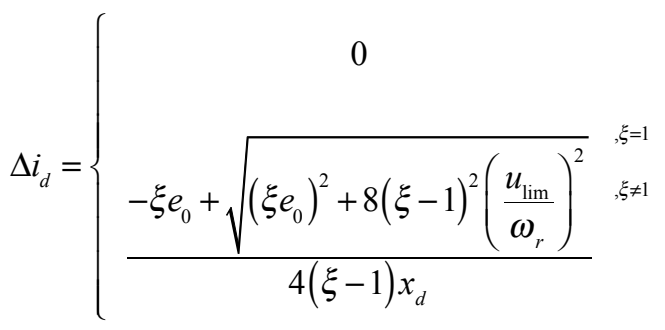

$\xi$ is salient pole coefficient of PMSM, for the SPMSM, the value is 1 , at this point the current on $d$-axis is a constant value, current on $q$-axis is proportional to speed, the control strategy is relatively more simple. In this paper, the subsection control strategy of SPMSM employs strategies in the first two cases.

\section{SYSTEM HARDWARE CONFIGURATIONS}

Based on this study, a $2.5 \mathrm{kw}$ SPMSM experiment platform is built; the control strategies of SPMSM in electric state are realized. The experiment platform includes several parts: the main circuit, the motor group and the control circuit.

\subsection{Power Supply and Test Unit}

As shown in Fig. (3), the experiment platform of SPMSM works in electric state. $3 \mathrm{kw}$ DC motor as a generator is connected with the SPMSM through a clutch; an adjustable resistance box as a load is connected with DC motor armature. The DC power supply of SPMSM driving system is composed of three-phase voltage regulator, three-phase uncontrolled rectifier module and filter capacitor. Adjust the 


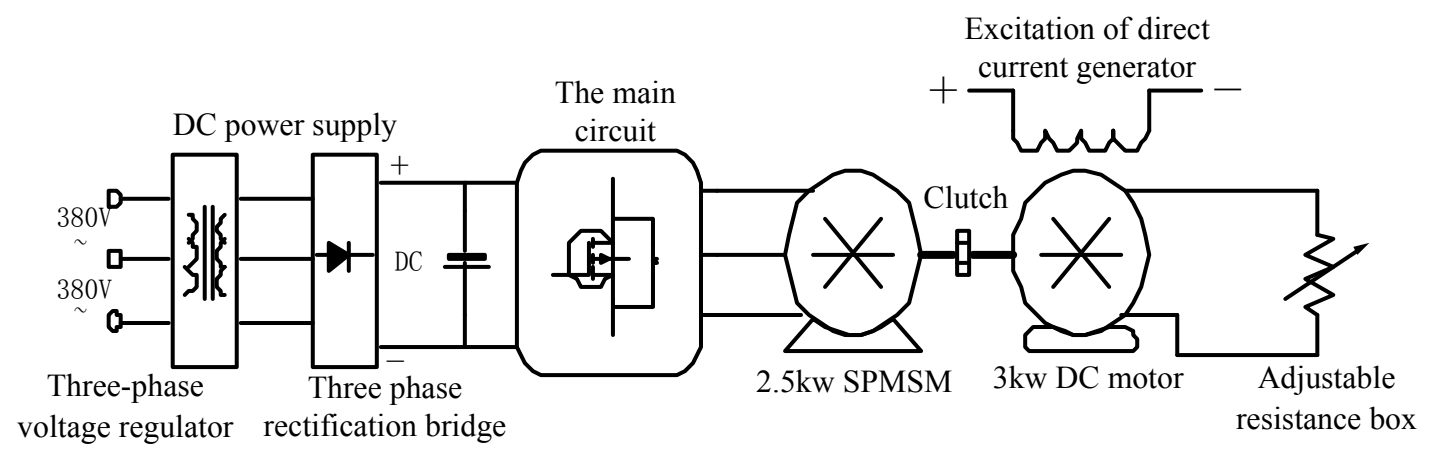

Fig. (3). Experiment Platform of SPMSM.

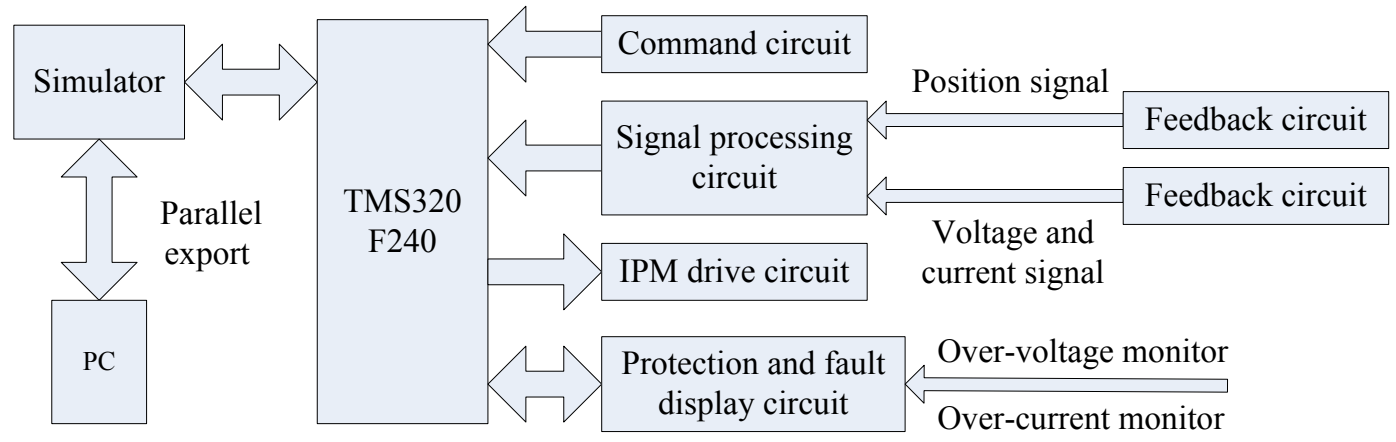

Fig. (4). Configuration of Control Circuit.

$50 \mathrm{kVA}$ three-phase voltage regulator to obtain different values of DC bus voltage. The SPMSM (IFT6072-6AC21-2-Z) is a production of Lanzhou motor factory, 6-pole, rated speed 2000rpm, rated voltage $128 \mathrm{~V}$, star connection, aircooled form; using the hybrid rotary optical encoder with a resolution of 2500 pulses. DC motor (Z2-41) is a production of Chongqing motor factory, rated power $3 \mathrm{kw}$, rated voltage $220 \mathrm{~V}$, excitation voltage $220 \mathrm{~V}$, rated speed $1500 \mathrm{rpm}[8,9]$.

\subsection{The Motor Controller}

The motor controller includes two parts: main circuit and control circuit.

1 Main circuit

The IPM module (PM150CSA060) is a production of Mitsubishi Company, rated current of single tube is $100 \mathrm{~A}$, and collector-emitter voltage of switch tube is $600 \mathrm{~V}$.

\section{Control circuit}

The control circuit includes a DSP digital signal processing chip, signal acquisition and I/O circuits, IPM driver protection circuit, etc, as an important part of the whole system, control circuit carries on feedback signal processing, control algorithm, SVPWM waves emitting, system overvoltage and over-current protection. A dedicated motor control DSP chip (TMS320F240) of U.S. TI Company is used in this control circuit, the configuration of control circuit is shown in Fig. (4) [10].
A complete control circuit includes a signal processing circuit, IPM drive circuit, protection and fault display circuit, command circuit and simulator interface circuit.

1) Signal processing circuit: Before the voltage and current signals and encoder signal send into the DSP chips, these signals should go through amplification, shaping, and simple logic operations and then enter the appropriate interface.

2) IPM drive circuit: The level signal from DSP's I/O interface must pass through the isolation amplifier to enter control terminal of the power devices. DSP I/O output signal is a TTL level signal, the driving voltage of the power module is $15 \mathrm{~V}$. For the IPM module containing six tubes, there must be at least four independent drive power supplies to prevent misoperation, switch of the upper bridge arm is an independent power supply, and the lower bridge arms share the same switch. To this end, a special IPM driver circuit must be designed, including the optical isolation circuit, $15 \mathrm{~V}$ DC power supply.

3) Protection and fault display circuit: In order to ensure the normal work, prevent over-voltage, over-current and over-temperature condition, prevent failure and damage to the system, control loop contains a protection circuit, in order to facilitate failure analysis, different LED flashes represent different fault types. 


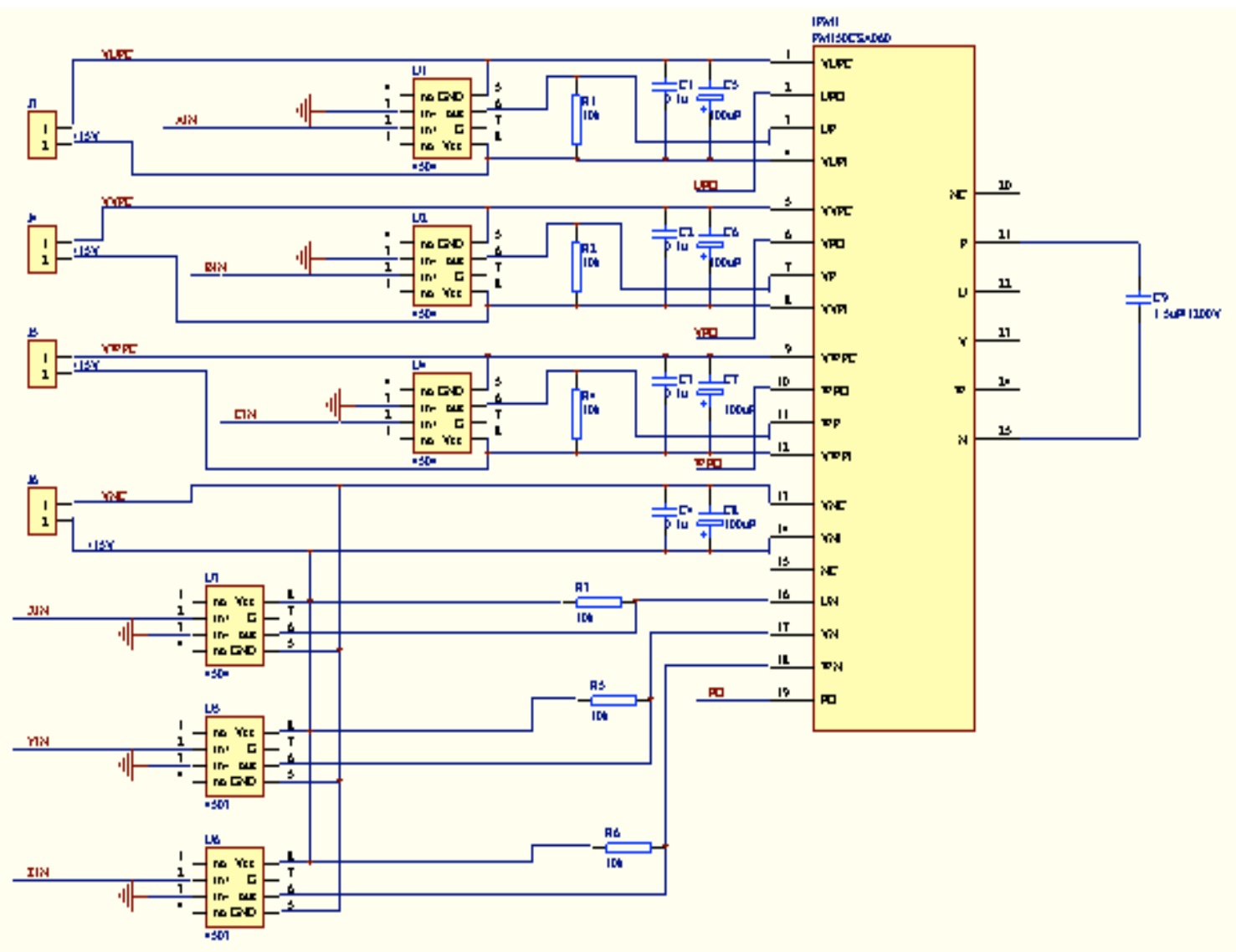

Fig. (5). Drive Circuit of PM150CSA060.

4) Command circuit: Command signals, such as positive and reversal signal, brake signal, given control amount (stator current, speed etc.), these signals need a special circuit to be sent to the DSP chip by I/O port.

5) Simulator interface circuit: Design of control system is realized by the external PC, therefore, there must be a corresponding interface circuit to complete the process of loading and running. The simulator used in this system is XP5110 plus emulator developed by TI Company, the control loop is connected through a parallel export between simulator and PC.

Signal processing circuit, protection and fault display circuit, command circuit and simulator interface circuit locate on the same board. In this paper, drive circuit board of IPM and power supply board of control circuit is redesigned. Drive circuit board of IPM is shown in Fig. (5), the input signal in the circuit includes drive signals (A Z) of IPM and protection signals (UFO, VFO, WFO), thus effectively protect IPM from being damaged. Power moderators have the appropriate voltage level of DC / DC modules.

\section{THE EXPERIMENT RESULTS}

Carry out SPMSM subsection control experiments on the hardware platform, the basic experiment including constant torque experiments with single loop, half voltage weak magnetic experiments etc. The set of experiments is mainly for the basic performance experiment of motor and its control system; verify the correctness of the control strategy.

\subsection{Constant Torque Experiments with Single Loop}

Set different stator current, and we can get the line voltage curves, line current curves, output torque curves, output power curves and motor speed curves, as shown in Fig. (6).

The motor current is set to $5 \mathrm{~A}, 10 \mathrm{~A}$ and $14 \mathrm{~A}$, it can be seen from the current-speed curve that, the value of actual phase current is slightly higher than given value, when the given current is close to the rated current, motor linearity deteriorates as the entry of the saturation. Considering the accuracy of the potentiometer and the experiment platform itself, we can think that the phase current is tracking the given value; the current-speed curve and torque-speed curve are basically consistent, for each given current, electromagnetic torque of the motor remained constant in the whole speed range; voltage and power of SPMSM rise rapidly with the change of speed.

According to the torque formula (4), when the $i_{d}=0$ control strategy is adopted in constant torque area, all the stator current are used to generate torque, and therefore at a given stator current, motor shows the characteristics of constant 

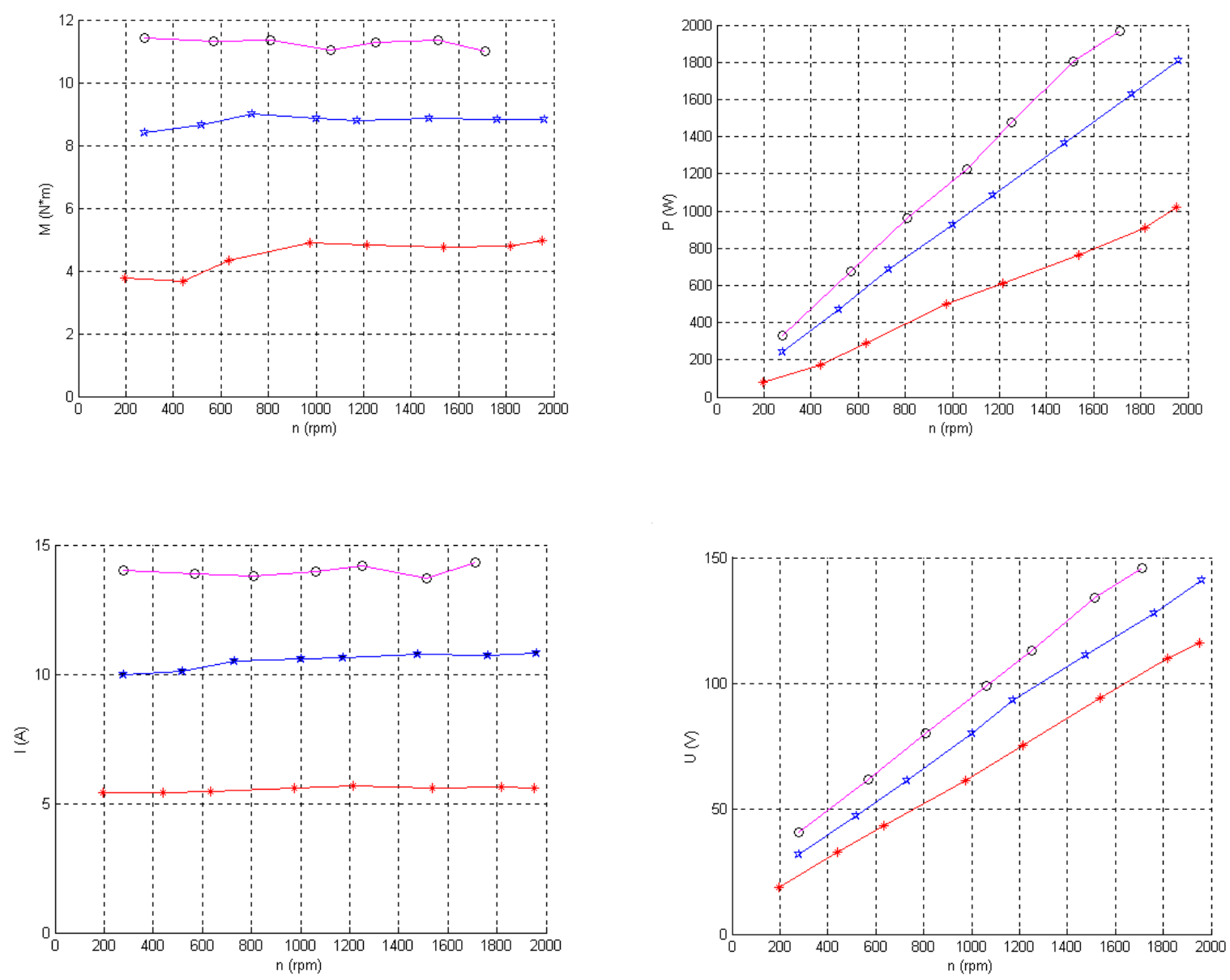

Fig. (6). Load Characteristics of 2.5kw SPMSM in Constant Torque Area.

torque output, terminal voltage of stator and output power rise linearly with the increasing speed. Load characteristics of SPMSM in constant torque area is shown in Fig. (6), this characteristic consistent with the conclusion, it can be considered that the vector control decoupling is successful.

\subsection{Half Voltage Weak Magnetic Experiments}

Restricted by DC motor, half voltage weak magnetic experiments are conducted to verify the correctness of the control strategy. In these experiments, the DC bus voltage is $U_{d c}=100 \mathrm{~V}$, value of stator current is given, the measured characteristics curves of SPMSM are shown in Fig. (7).

As can be seen from Fig. (7): When the current is given as $5 \mathrm{~A}$ and $12 \mathrm{~A}$, given current is basically agreed with the current-speed curve; at current of $5 \mathrm{~A}$, the turning speed is about $1000 \mathrm{rpm}$, at $12 \mathrm{~A}$, the turning speed is about $700 \mathrm{rpm}$; In both cases, the maximum speed of the motor is $1700 \mathrm{rpm}$ and $2000 \mathrm{rpm}$ respectively. In these experiments, the voltage and current are measured by the measuring instrument directly and the measurement error can be limited in a certain range. The output torque and output power are calculated indirectly, loss error of DC motor is inevitable, the accuracy of the motor output torque and output power will be affected to a certain extent; nevertheless, it can be proved that the subsection control strategy of SPMSM in the experiment is correct.

\section{CONCLUSION}

Based on the mathematical model of PMSM, according to the characteristics of PHV, a subsection control strategy is designed for SPMSM in electric state. The experiment platform of control system is built, the closed-loop control of the driving system for $2.5 \mathrm{kw}$ SPMSM is realization, load control experiments that run below the base speed and no-load weak magnetic operation experiments that run above the base speed are carried out. Experiments show that: when the $i_{d}=0$ control strategy is adopted in constant torque area, all the stator current are used to generate torque, and therefore at a given stator current, motor shows the characteristics of constant torque output, terminal voltage of stator and output 

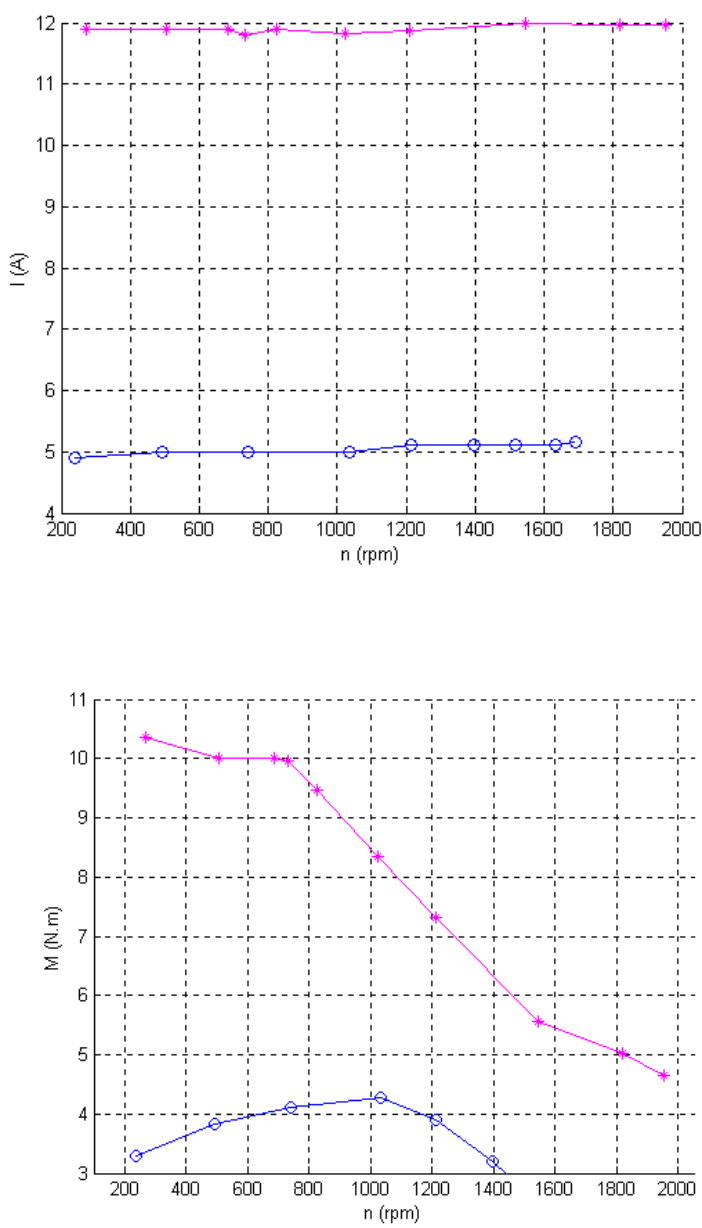
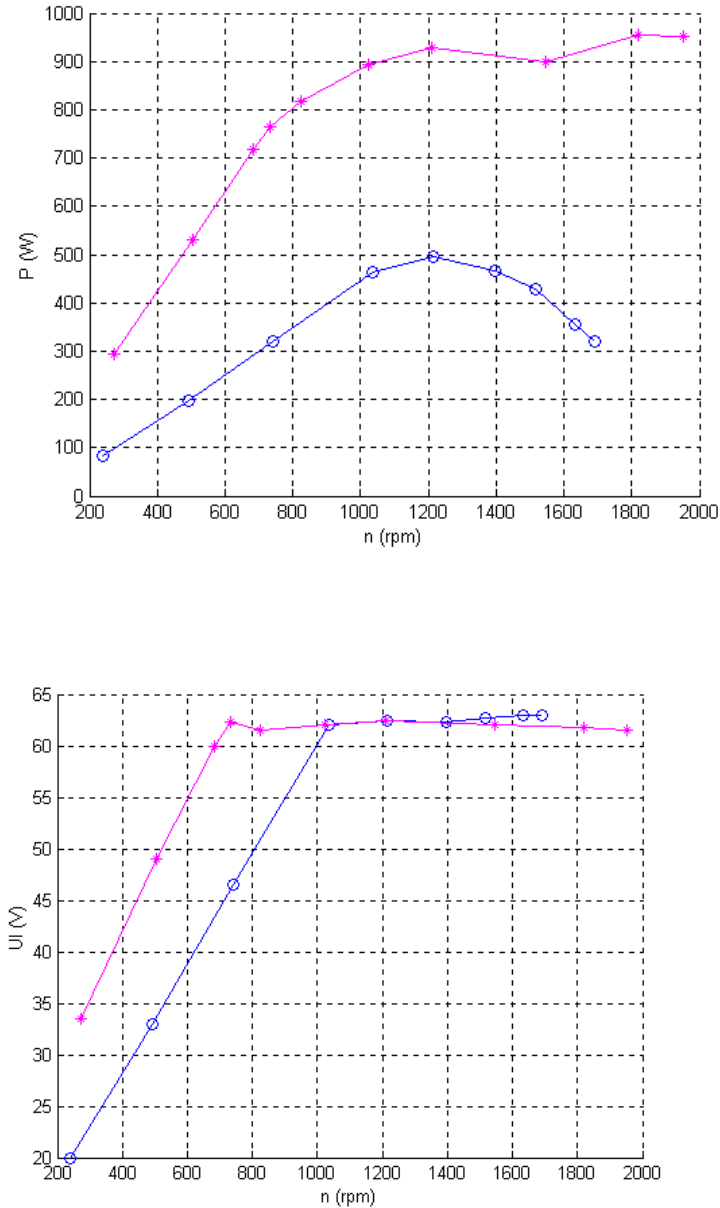

Fig. (7). Load Characteristics of 2.5kw SPMSM in Subsection Control Strategy.

power rise linearly with the increasing speed; when the weak magnetic control strategy is adopted and the SPMSM run above the base speed, load characteristics of SPMSM are consistent with the expectation, the vector control decoupling is successful. It can be considered that: in electric state, the application of the control strategy has achieved the desired control objectives.

\section{CONFLICT OF INTEREST}

The authors confirm that this article content has no conflicts of interest.

\section{ACKNOWLEDGEMENTS}

This research was financially supported by the National Natural Science Foundation of China (No.51305112).

\section{REFERENCES}

[1] WANG Minggui, WANG Jin-yi, "Electric vehicle and its performance optimization", China Machine Press, 2010.
[2] LIU Tingting, TAN Yu, and WU Gang, "Simulating of high speed PMSM control system based on SVPWM", Power System Protection and Control, Vol. 37, Issue 12, 2009, pp. 11-14,19.

[3] HUANG Surong, ZENG Feng, and HONG Wencheng, "Design and simulation of control system of ISG permanent magnet synchronous motor for hybrid electric vehicles", Electric Machines \& Control Application, Vol. 34, Issue 11, 2007, pp. 18-22.

[4] Li Yaohua, Ma Jian, Liu Jingyu, and Yu QiangA, "Comparative study on the control strategies of permanent magnet synchronous motor drives for electric vehicles", Automotive Engineering, Vol. 35, Issue 5, 2013, pp. 413-417,412.

[5] Zhang Jingming, Ren Dianbo, Niu Xiaojing, and Cui Shumei, "Application of PMSM vector control system in PHEV", Journal of Jiangsu University(Natural Science Edition), Vol. 32, Issue 2, 2011, pp. 157-162.

[6] Lakshmi, G.S., Kamakshaiah, S., and Das, T.R., "Closed loop PI control of PMSM for hybrid electric vehicle using three level diode clamped inverter for optimal efficiency", 2013 International Conference on Energy Efficient Technologies for Sustainability, Nagercoil, India, April 2013, pp. 754-759.

[7] Xianqing Cao, Liping Fan, "Flux-weakening control scheme based on the fuzzy logic of PMSM drive for hybrid electric vehicle", 2009 IITA International Conference on Control, Automation and Systems Engineering, Zhangjiajie, China, July. 2009, pp. 287-290.

[8] Dai Ying Song, Li-wei, and Cui Shu-Mei, "Development of PMSM Drives for Hybrid Electric Car Applications in Magnetics", IEEE Transactions, vol.43, issue:1, Jan.2007, pp.434-437. 
[9] Nordlund, E, "The Four-Quadrant Transducer System for Hybrid Electric Vehicles", Ph.D. Thesis, Royal Institute of Technology, Stockholm, Sweden, May 2005.
[10] LIU Yong, TONG Chengde, SUI Yi, and YAN Haiyuan. "Hardware design on control system of compound structure permanent magnet", Micromotors, Vol. 43, Issue 7, 2010, pp. 44-46,56.

Received: September 16, 2014

(C) Liu and Li; Licensee Bentham Open.

This is an open access article licensed under the terms of the Creative Commons Attribution Non-Commercial License (http://creativecommons.org/licenses/by-nc/3.0/) which permits unrestricted, non-commercial use, distribution and reproduction in any medium, provided the work is properly cited. 